\title{
Sustainable nanotechnology decision support system:bridging risk management, sustainable innovation and risk governance
}

\author{
Vrishali Subramanian, Elena Semenzin, Danail Hristozov, Alex Zabeo, Ineke Malsch, Eamonn McAlea, \\ Finbarr Murphy, Martin Mullins, Toon van Harmelen, Tom Ligthart, Igor Linkov, Antonio Marcomini
}

V. Subramianian E. Sėmenzin D. Hristozov A. Zabeo I. Linkov A. Marcomini - Department of Environmental Sciences, Informatics and Statistics, University Ca' Foscari of Venice, Venice, Italye-mail: marcom@unive.it

I. Malsch - Malsch TechnoValuation, Utrecht, The Netherlands

E. McAlea F. Murphy M. Mullins - Kemmy Business School, University of Limerick,Limerick, Ireland

T. van Harmelen T. Ligthart-TNO, Utrecht, The Netherlands

I. Linkov- US Army Engineer Research and Development Center,Concord, MA, USA

\begin{abstract}
The significant uncertainties associated with the (eco)toxicological risks of engineered nano- materials pose challenges to the development of nano-enabled products toward greatest possible societal benefit. This paper argues for the use of risk governance approaches to manage nanotechnology risks and sustainability, and considers the links between these concepts. Further, seven risk assessment and management criteria relevant to risk governance are defined: (a) life cycle thinking, (b) triple bottom line, (c) inclusion of stakeholders, (d) risk management, (e) benefitrisk assessment, (f) consideration of uncertainty, and (g) adaptive response. These criteria are used to compare five well-developed nanotechnology frame- works: International Risk Governance Council frame- work, Comprehensive Environmental Assessment, Streaming Life Cycle Risk Assessment, Certifiable Nanospecific Risk Management and Monitoring System and LICARA NanoSCAN. A Sustainable Nanotechnology Decision Support System (SUNDS) is proposed to better address current nanotechnology risk assessment and management needs, and makes.Stakeholder needs were solicited for further SUNDS enhancement through a stakeholder workshop that included representatives from regulatory, industry andinsurance sectors. Workshop participants expressed the need for the wider adoption of sustainability assessment methods and tools for designing greener nanomaterials.
\end{abstract}

Keywords Decision support system - Sustainablenanotechnology $\cdot$ Risk governance $\cdot$ Risk management Engineered nanomaterials

\section{Introduction}

Nanotechnology is one of the Key Enabling Technologies identified in the European Union (EU) 2020 Strategy, which is expected to enhance economic growthand industrial competitiveness (COM(2009)512, COM(2012)341). While there is no precise informationon market penetration of engineered nanomaterials (ENM), consumer nanoenabled product inventories have been registering an increasing number of nano- enabled products over the past years (Nanodatabase 2015, Project on Emerging Nanotechnologies Product Inventory 2015). While the global nanotechnology valuechain is expected to reach $\$ 4.4$ trillion by 2018 (Lux Research 2014), large uncertainties persist about the environmental, health and safety (EHS) risks of ENM.Moreover, there is a significant time lag between nano-EHS data availability and its use by regulatory agenciesto perform risk assessment (RA) and risk management(RM). These challenges, together with ambiguous perceptions of risks, economic viability and social impactsmay potentially impede the realization of the full value ofnanotechnology Research and Development.

Credible RA can be used to inform RM to protectthe safety of workers, downstream value chain,consumers and the environment. However, the application of the RA methods that are in practice forconventional chemicals to ENM is hampered bysignificant uncertainty and variability (Hristozov et al. 2015, 2012). Risk can be defined as an estimateof hazard and exposure leading to adverse effectswhich are likely to occur in a human population orenvironmental compartment due to exposure to asubstance (Van Leeuwen and Vermeire 
2007). RA hasbeen used for regulatory decision-making for chemicals (EU Regulation 1907/2006), biocides (EU Regulation 528/2012), food (EU Regulation 258/1997,1333/2008), cosmetics (EU Regulation 1223/2009), medical devices (EU COM (2012) 542), but emergingnature of nanotechnology risks results in disconnectbetween risk assessment and risk management, giventhe dynamic nature of the threats and socio-politicalambiguity (Linkov et al. 2014, 2009). This trend isexpected to continue, with even more complexity anduncertainty associated with future generations of nanotechnologies (IRGC 2012; Subramanian et al. 2010). Risk governance has been proposed as a complimentary approach in order to address these existinginadequacies of RA for ENM (Linkov et al. 2009).Risk Governance is defined as a unifying approach todecision-making that involves the actors, conventions, rules and processes concerned with how relevant riskinformation is collected, analysed and communicatedin order to enable more effective risk management thatis convergent with other public and private policies(IRGC 2012). Specifically, risk governance takes intoaccount the broader scientific and societal context within which risks occur in order to support decision-making that minimizes risks and maximizes benefits to stakeholders. While risk governance and sustainabilityhave not been explicitly linked ${ }^{1}$; the goal of risk governance is to reduce risk by filling gaps in risk policy in order to avoid or reduce social, environmental or economic costs (Renn and Roco 2006) directly relevant to goal of sustainable development (Subramanian et al. 2014). Renn (2008) relates risk governance and sustainability by positing sustainability as the outcome of successful risk governance process over longer time scales.

Both Risk Management and Risk Governance require structured methods and tools that can connectdata and provide confidence in evaluation with the given scientific uncertainties and varying management goals. The nanotechnology value chain comprises multiple actors with diverse goals, perspectives and needs that need to be aligned in charting a viable trajectory for specific nano-enabled technologies and products (NNI Report 2015). Both Risk Managementand Risk Governance methods and tools need to be built on what is known about risks and involving various actors, perspectives, goals and activities in balancing the perceived risks of ENM with the potential benefits arising from their innovative applications. The EU FP7 project on Sustainable Nanotechnologies (SUN http://www.sun-fp7.eu/) aims to achieve this through developing an overarching decision analytical framework for analysis and management of nanotechnology risks and implementing it as asoftware-based decision support system (DSS) for practical use by industries, insurance sector and regulators. The aim of this paper is to present and discussSUN DSS framework in the light of its value for nanotechnology risk governance.

\section{Evaluation of existing risk management and sustainable nanotechnology frameworkscontribution toward nanotechnology risk governance}

Literature published over the past 3 years and resultsof ongoing projects show an increasing focus on RM frameworks related to ENM and nano-enabled products (see Hristozov et al. 2015 for a comprehensive overview). This literature contains a few frameworks that have been described in detail to allow comparison, as performed by Greiger et al. (2012a, b) and Hristozov et al. (2012). In addition to RM frameworks, we also searched for sustainable nanotechnology frameworks. The literature on sustainable nanotechnology has almost doubled as of September 2015(53,900 results in Google Scholar) as compared to 2009-2011 period (32,300 results). However, only one sustainable nanotechnology framework has been pro-posed in this literature namely LICARA NanoSCAN framework (Som et al. 2014). The following frame- works were selected for comparison as they significantly addressed components of nanotechnology risk assessment and management: International Risk Governance Council (IRGC) framework (IRGC 2012), Comprehensive Environmental Assessment (CEA) (Powers et al. 2012), Certifiable Nanospecific Risk Management and Monitoring System (CENARIOS ${ }^{\circledR}$ ) (TÜV SÜD 2013), Streamlined Life Cycle Risk Assessment (SLCRA) (Shatkin 2012), and LICARA NanoSCAN framework (Som et al. 2014).

The selected frameworks are diverse in terms of their purpose, structure and application, so comparative evaluation requires the use of relevant criteria for risk assessment and management (which are relevant components in risk governance). Two criteria were extracted from comparison of RM frame- works in Greiger et al. (2012a) and Hristozov et al. (2012), namely life cycle thinking and uncertainty estimation. The remaining five criteria were extractedfrom the white papers of IRGC framework (IRGC 2005, 2010, 2012, 2015). The IRGC white papers support the inclusion of the criteria from Greiger et al. (2012a) and Hristozov et al. (2012). While IRGC 
explicitly mentions only environmental andsocial deficit categories of risk governance, some examples mentioned in the description of these categories include macroeconomic impacts like inter-national trade and job loss (IRGC 2012). Thus, sustainability as expressed by triple bottom line (TBL) can also be included as a component of nanotechnology risk governance. Seven evaluative criteria can be extracted for nanotechnology risk assessment and management:

a) Life cycle thinking Life cycle thinking expands the focus on the production site and manufacturing processes and incorporates various aspects over a product's entire life cycle from extraction of resources to the final processing of the disposed product. The incorporation of life cycle thinking is desirable for nanotechnology risk governance in order to avoid "problem shifting"' to other life cycle stages.

b) Triple bottom line The Ethical Legal and SocialImplications (ELSI) literature on nanotechnology suggests that in addition to environmental impacts, nano-enabled products also trigger important social and economic impacts (Seear et al. 2009). A sustainable nanotechnology framework based on TBL criteria through the life cycle can be used to monitor the environmental, economic and social impacts of nanoenabled products.

c) Inclusion of stakeholders Stakeholders have diverse perspectives and needs with respect to nanotechnology risk assessment and management, as illustrated by literature on the needs ofindustry (Conti et al. 2008; Engeman et al. 2012; Maynard 2015; Malsch et al. 2015b),regulators (Malsch et al. 2015b) and insurance sector (Blaunstein and Linkov 2010; Baublyte et al. 2014; Mullins et al. 2013). The National Nanotechnology Initiative conducted a work- shop in 2013 that elicited nanotechnology stakeholder needs with respect to communication resources, data resources, standards and guidance resources and decision tools (NNI Report 2015), and serves as a good illustration of the need to address diverse stakeholder perspectives.

d) Risk management Risk assessment and management frameworks should provide prescription on how to manage risks ensuing from nanotechnologies. RM has both technical and organizational components that should be addressed by the nanotechnology risk governance framework. Further, it is desirable that the risk governance framework should provide a clear RM prescription i.e. there should be a strong link between the risk assessment or impact assessment with its management.

e) Benefit-risk assessment In order to assess the societal value of nano-innovation, risk assessment and management frameworks should assess the balance between benefits and risks (or costs) of nano-enabled products. Benefit- risk balance is a principle mentioned in many regulatory frameworks, but usually the strongest focus tends to be the risks and costs. It is important that nanotechnology risk governanceis based on a more holistic assessment that alsoconsiders its societal value.

f) Consideration of uncertainty There are significant knowledge and data gaps in physicochemical properties, fate and transport, exposure anduptake, and (eco)toxicity of ENM (Hristozovet al. 2015). Nanotechnology risk assessment and management frameworks should explicitlyaccount for this uncertainty, and communicate clearly the nature and magnitude of the uncertainty to the stakeholders.

g) Adaptive response to new information Given thedynamic nature of nanotechnology EHS, risk assessment and management frameworks shouldalso be flexible to adapt to completely newinformation. This is particularly relevant with regard to bridging risk governance and sustainability over longer time scales (Renn 2008). An adaptive response to environmental management isbased on monitoring a range of management alternatives and their implementation outcomes toimprove knowledge of the system being managedover time (Gunderson 2001; Linkov et al. 2006).

Table 1 compares performance of the most cited frameworks with respect to the seven criteria presented above. As reported in Table 1, all the selected frameworkssatisfy the first criterion by including life cycle thinking, although in different ways. In the nanosafetycontext, three recommendations can be identified made toward integrating RA and life cycle assessment(LCA): (a) life cycle-based RA, which involves applying life cycle perspective to conventional RAto identify hotspots of risk (Sweet and Strohm 2006; Som et al. 2010; Greiger et al. 2012b), (b) RA- complemented LCA, which involves applying conventional LCA to identify hotspots to which RA will be applied (Greiger et al. 2012b; Barberio et al. 2014), and (c) Use of decision analysis, which suggests use 
of multicriteria decision analysis (MCDA) to integrate RA and LCA as criteria (Linkov and Seager 2011; Som et al. 2014). While LICARA NanoSCAN adoptsuse of decision analysis, all other frameworks com- pared in this paper adopt life cycle-based RA.

Among the studied frameworks, only LICARA NanoSCAN decision framework addresses all TBL pillars (second criterion in Table 1). IRGC frameworkand CENARIOS standard propose an emphasis on nanotechnology ELSI and effective risk communication (i.e. social pillar), along with a main focus on nanosafety (i.e. environmental pillar), but do not focusupon the economic pillar. Finally, CEA and SLCRA are proposed life cyclebased RA, which address onlythe environmental pillar.

As far as the criterion inclusion of stakeholders isconcerned, except the CENARIOS standard andSLCRA, all frameworks prescribe or utilize inclusionof stakeholder perspectives (Table 1). The IRGCframework strongly emphasizes the need for engagement with a broad base of experts and stakeholders inthe case of complex and uncertain risks (IRGC 2007).A US Environmental Protection Agency (EPA)workshop used nominal group technique (NGT) toprioritize expert discussions on nano-EHS researchneeds for three ENM (USEPA 2010, 2012a, b), andbroader group of sector and disciplinary expertise wasalso involved using an interactive web-based tool formultiwalled carbon nanotube-based flame retardant(Powers et al. 2014). LICARA NanoSCAN was built in close collaboration with a small and mediumenterprise (SME) association as well as individualSME as consortium partners in order to fully addressnano-enabled product manufacturing needs of SMEs. The fourth criterion in Table 1, Risk management,

is addressed only in the case of three studied frame- works: IRGC, CENARIOS standard and LICARANanoSCAN. The IRGC framework provides general, technical, institutional and communication recommendations to manage risks. The CENARIOS standard is an organizational risk management system thatposits specific risk management guidelines based on International Standards Organization (ISO), Austrian Standards Institute's (ON) rules and Federation ofEuropean Risk Management Associations (FERMA) for organization, staff, risk monitoring and communication. The LICARA NanoSCAN framework addresses occupational risk management through Stoffenmanager Nano tool, which assesses the impactof risk management measures on the occupational riskscore. None of the compared frameworks studied advance a quantitative way to link risk assessment andmanagement (Oksel et al. 2015).

Table 1 Performance of frameworks on nanotechnology risk assessment and management needs

\begin{tabular}{|c|c|c|c|c|c|}
\hline & IRGC & CEA & SLCRA & $\begin{array}{l}\text { CENARIOS } \\
\text { standard }\end{array}$ & $\begin{array}{l}\text { LICARA } \\
\text { NanoSCAN }\end{array}$ \\
\hline 1. Life cycle thinking & Yes & Yes & Yes & Yes & Yes \\
\hline 2. Triple bottom line & $\begin{array}{l}\text { Environmental and } \\
\text { social pillar }\end{array}$ & $\begin{array}{l}\text { Environmental } \\
\text { pillar only }\end{array}$ & $\begin{array}{l}\text { Environmental } \\
\text { pillar only }\end{array}$ & $\begin{array}{l}\text { Environmental and } \\
\text { social pillar }\end{array}$ & Yes \\
\hline 3. Inclusion of stakeholders & Yes & Yes & No & No & Yes \\
\hline 4. Risk management & Yes (qualitative) & No & No & Yes (qualitative) & $\begin{array}{l}\text { Yes (semi- } \\
\text { quantitative) }\end{array}$ \\
\hline 5. Benefit-risk assessment & No & No & No & No & Yes \\
\hline $\begin{array}{l}\text { 6. Consideration of } \\
\text { uncertainty }\end{array}$ & Yes & No & No & No & Yes \\
\hline $\begin{array}{l}\text { 7. Adaptive response to } \\
\text { new information }\end{array}$ & Yes & Yes & Yes & Yes & Yes \\
\hline
\end{tabular}

Benefit-risk assessment of nano-enabled products is addressed only by LICARA NanoSCAN (fifth criterion in Table 1). The IRGC framework is based on a deficit model, in which risks/costs need to be minimized, but this is not balanced with the benefits ofthe nano-enabled product. Benefit-Risk balance iscritical to risk assessment and management, and moreinformation is needed on benefits of specific nanotechnologies and nano-enabled products for a more holistic assessment of alternatives.

Of the considered frameworks, only IRGC andLICARA NanoSCAN take uncertainty into consideration (sixth 
criterion in Table 1). The IRGC framework describes the use of precaution-based (e.g. As Low as Reasonably Achievable principle, Best Available Control Technologies) and resilience- based (e.g. preparedness for adaptation) strategies in the face of systemic uncertainties. LICARA NanoSCAN utilizes Information Gap Theory to consider the sensitivity of missing parameters in the decision model. None of the frameworks recommend using quantitative uncertainty estimation techniques (e.g.Monte Carlo simulations).

Finally, all frameworks have some amount of adaptability to new information (the last criterion in Table 1). IRGC and CENARIOS standard address thiscriterion by suggesting that TBL impacts of nanotech-nology should be actively monitored over time. All other frameworks have a defined conceptual frame- work that accepts new data as nanotechnology risks and impacts improve over time.

The comparison of frameworks above shows that while all of them incorporate life cycle thinking, noneof the frameworks satisfy all the remaining criteria. The LICARA NanoSCAN is the one addressing all ofthe criteria.

\section{SUNDS conceptual decision framework}

SUNDS conceptual decision framework aims to address the lacunae in existing frameworks. A two- tiered framework was designed to address differing data availability and expertise of stakeholders to handle analytical complexity. This framework is described in the sub-sections below.

\section{$\underline{\text { SUNDS Tier } 1}$}

SUNDS Tier 1 comprises LICARA NanoSCAN, a tool developed within the FP7 LICARA project (www. licara.eu) specifically for SMEs. As SMEs have limited time and internal expertise to carry out complex analyses, LICARA NanoSCAN is designed as a user-friendly, screening-level tool that assists SMEs inchecking supplier risks, competing products, market opportunities or making an internal risk and benefit analysis. To achieve this, the tool integrates RA and LCA using MCDA to provide a semi-quantitativeevaluation of the environmental, social and economicbenefits and the ecological, occupational and consumer health risks of nano-enabled products fromlife cycle perspective in comparison to conventional products with similar uses and functionality (van Harmelen et al. 2016; Som et al. 2014). The conceptual framework of LICARA NanoSCAN is provided in Fig. 1.

LICARA NanoSCAN is modular and contains eight sections. The questions involved in each section are qualitative and semi-quantitative and can thus be answered without detailed data (e.g. yes, no, unknown). Uncertainty is estimated by user input (selecting 'unknown') or unanswered questions; in which case a worst case scenario is used (specifying the most negative answer).

Module 0 assesses the nano-relevance of the product that is being evaluated in terms of whether it contains nanomaterials and provides current EU and International Standards Organization (ISO) definitions of ENM.

Modules 1-3 aim to compare environmental, economic and societal benefits between nano-enabledproducts and conventional products. Results of these modules are presented on a scale from -1 to 1 . A score close to -1 indicates that the nano-enabled product is worse than a conventional product; a score close to 0 indicate that they are similar; while a score close to 1 indicates that the nano-enabled product is better than the conventional product.

Modules 4-6 aim to assess public health and environmental risks, occupational health risk and consumer risks of the nano-enabled products. Module4 utilizes Precautionary Matrix (Höck et al. 2013), Module 5 utilizes Stoffenmanager Nano (Van Duuren-Stuurman et al. 2012), and Module 6 utilizes Stoffenmanager Nano (Van Duuren-Stuurman et al. 2012) and NanoRiskCat (Hansen et al. 2011). The results of these modules are not comparative and presented on ascale of $0-1$. Scores below 0.3 indicate low risks; scores between 0.3 and 0.7 indicate moderate risks, and a score higher than 0.7 indicates a high risk.

Module 7 synthesizes the results of Modules 1-6 into a two-dimensional risk-benefit space that is divided into four quadrants with respect to nano- enabled product development: Go ahead, Cancel/ Rethink, Further research needed and Other benefits required. Especially in the case that the results are located in the centre ("Undecided"), the user is advised to move to SUNDS Tier 2. 


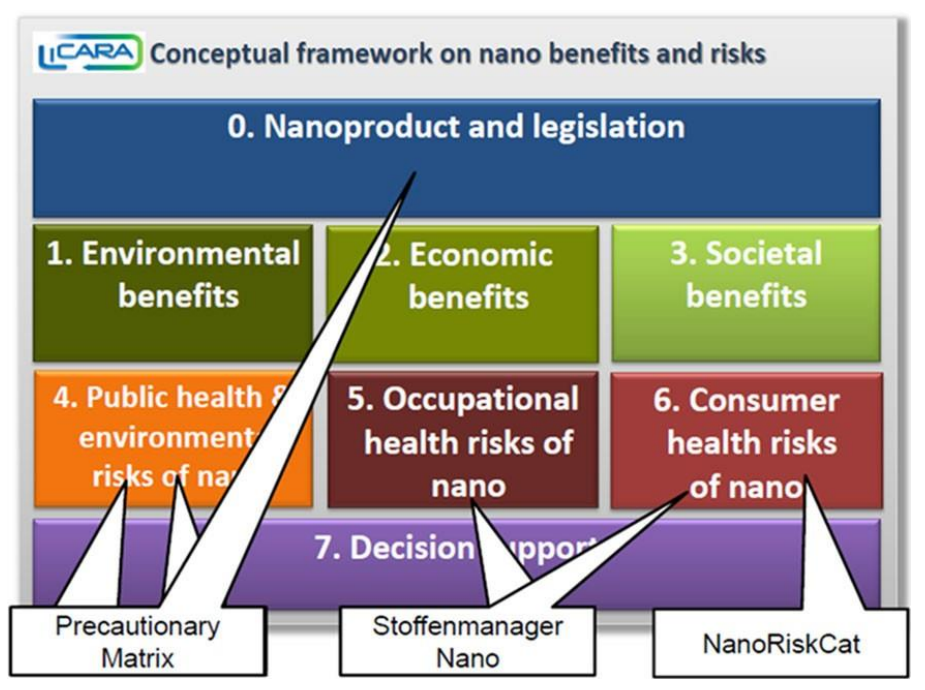

Fig. 1 Conceptual Framework for LICARA NanoSCAN

LICARA NanoSCAN has been tested to the case offour nano-enabled products, with additional corroboration from in depth RA and LCA: (1) A Polymer Electrolyte Membrane fuel cell containing multi- walled carbon nanotubes, (2) an antibacterial nanosil-ver coating for door handles in hospitals, (3) nanosilver in a microfiber cloth, and (4) a façade coating containing nanotitanium dioxide. van Harme-len et al. (2016) reports that there is good agreement ofLICARA NanoSCAN and in depth assessment for the fuel cell and façade coating. For the other two case studies, LICARA produced results that were more positive (in the case of antimicrobial fiber cloth due todetailed information on reference product) or negative(in the case of antibacterial coating due to magnitude of social benefit). The reliability of the results ofLICARA NanoSCAN can be improved using corroboration with in depth assessment (van Harmelen et al.2016), and these measures can be easily implemented within SUNDS Tier 2. Application to case studies andstakeholder feedback suggested that significant value of the LICARA NanoSCAN framework lies in the facilitation of discussion on the sustainability of nano-enabled products and an indication of how it can be potentially improved.

\section{$\underline{\text { SUNDS Tier } 2}$}

SUNDS Tier 2 comprises more advanced tools tosupport sustainable nanotechnology. A stand-alonemodule based on CENARIOS standard has also been included in order to enable users to assess the effectiveness of their organizational risk management practices (TÜV SÜD 2013; Widler et al. 2016).

Figure 2 presents the conceptual framework for SUNDS Tier 2.

SUNDS Tier 2 has the following sub-modules:

Ecological risk assessment (ERA) sub-module derives ecological risk by integrating outputs from:

(a) an environmental exposure model that estimates Predicted Environmental Concentrations (PECs) indifferent environmental compartments (e.g. water, soil), and (b) deterministic procedures or species sensitivity distributions (SSDs) (ECHA 2012) that estimate Predicted No-Effect Concentrations (PNECs) for various species in the ecosystem in these compartments. Resulting ecological risk will be eitherdeterministic (i.e. PEC/PNEC <1) or probabilistic (i.e. potentially affected fraction of species $<0.05$ ) depending on the nature of exposure and effect input data. Themethodology for exposure and effect estimation and its application to case studies can be found in other publications (Gottschalk et al. 2015, 2013; Semenzin et al. 2015; Sun et al. 2014).

Public health risk assessment sub-module estimates the risks for humans exposed to nanomaterials via the environment by integrating outputs from: (a) the environmental exposure model described above, and (b) deterministic and probabilistic procedures for dose-response assessment and intra/inter-species 
extrapolations. The resulting estimation of human health risk will be always quantitative, but either deterministic (exposure dose/derived no-effect level (DNEL) $<1$ ) or probabilistic (e.g. $5 \%$ of the population has at least a $10 \%$ response with $95 \%$ confidence) depending on the nature, quantity and quality of the input exposure and effects data.

Occupational and consumer human health risk assessment (HHRA) sub-module derives occupational and consumer health risk by integrating outputs from:

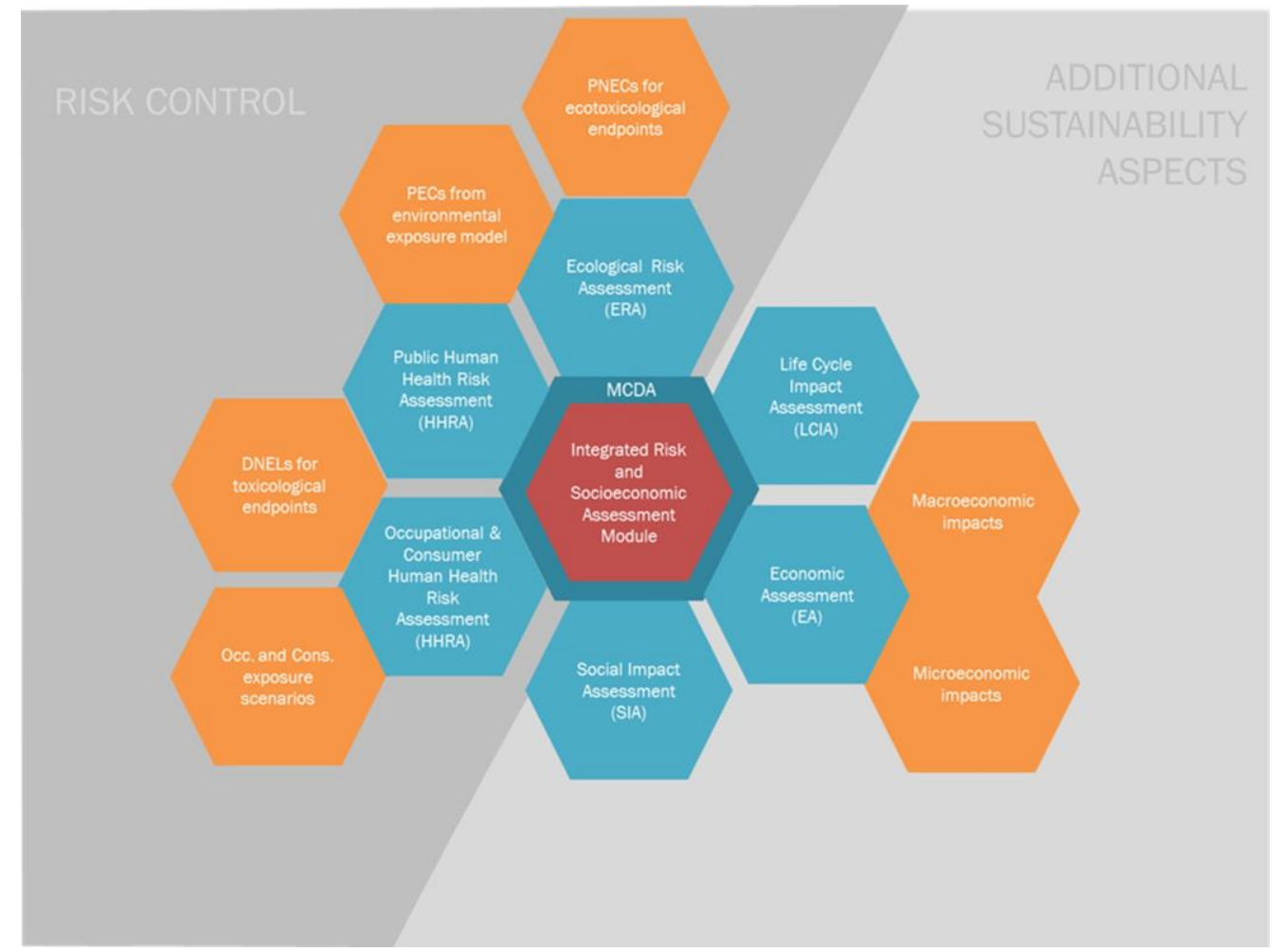

Fig. 2 SUNDS Tier 2 conceptual decision framework

(a) Human health exposure model that assesses relevant occupational and consumer exposure scenar-ios according to three tiers (i.e. qualitative, semi-quantitative and quantitative) and taking into accountthe effect of applied risk management measures (RMMs), and (b) the above deterministic and probabilistic procedures for dose-response assessment and intra/inter-species extrapolations.

Life cycle impact assessment (LCIA) sub-module uses tools that employ LCA midpoint methods for each life cycle stage [e.g. ReCiPe (Goedkoop et al. 2009)]. These indicators will be weighed using shadow prices (van Harmelen et al. 2007; De Bruynet al. 2010) or national-level statistical data and subsequently aggregated in order to obtain a finalscore.

Economic assessment (EA) sub-module assessesmicroeconomic impacts for each life cycle stage of a nanoenabled product. This module implements a costevaluation methodology that considers the cost ofcapital, material, manufacturing inputs, regulatory compliance, risk management and benefits at the individual company level for the functional unit underconsideration. An insurance cost assessment method-ology will also be included in this submodule that estimates an insurance premium that internalizes the economic externalities of creation and management ofrisk.

Social impact assessment (SIA) sub-module assesses social impacts through the life cycle due toa nano-enabled product (Althaus 2009). This sub-module will focus upon quantitative evaluation ofsocial impacts, classified as benefit or cost, to workersand community stakeholders. Its methodology andapplication to a case study is presented in Subramanian et al. (2016). 
Like SUNDS Tier 1, SUNDS Tier 2 is based on theintegrated evaluation based on Risk control (RC) (ECHA 2011a) and socioeconomic analysis (SEA) (ECHA 2011b). In the RC module in Tier 2, the best risk control strategies will be assessed for scenarios ofnano-enabled product development. Toward this end, outputs of ERA and HHRA submodules will be ranked according to efficiency and cost using an inventory that includes safety-by-molecular designsolutions, personnel protective equipment and engineering controls. An inventory of technological alternatives and risk management measures (TARMM) ranks TARMM relevant to specific exposure scenarios according to their efficiency and cost using questionnaire and data from literature and ongoing projects (Oksel et al. 2015).

The SEA module in Tier 2 will integrate outputs ofERA, HHRA, LCIA, EA and SIA sub-modules using user preference profiles to compare scenarios of nano-enabled products with each other or conventional product. While mathematical integration to produce asingle score is possible, the interpretation of such an output is not clear or theoretically supported by the sustainability literature. Thus, the SEA module pro- vides a snapshot of various sustainability criteria, classified according to users' preference profiles, to support decision-making.

\section{SUNDS framework and stakeholder needs}

The proposed framework was presented at a stake- holder workshop held at Utrecht (NL) in October 2014to representatives of potential users of SUNDS. The workshop included twenty-four participants, andattendance by core stakeholders was as follows: six regulator representatives (risk assessors and policy- makers), three representatives from industry and three representatives from insurance sector. The remaining participants comprised of researchers and tool developers. Arguably, sustainability of the nanotechnologysector is dependent on a broader range of stakeholders(e.g. workers, consumers and the general public). We focussed upon regulators, industry (small and large) and insurance sector representatives as they are the intended users of the SUNDS tool. The stakeholders recognized the potential utility of the SUN conceptualdecision framework and offered feedback on the decision analytic framework and other tools proposedto be included in SUNDS (http://www.sun-fp7.eu/ summary-report-on-sun-stakeholder-workshop/).

Based on thematic analysis of transcript of work- shop discussions, it was possible to extract the stakeholder preferences for the following sustainability assessment methods: screening and advanced RA [RA(s) and RA(a)], screening and advanced LCA[LCA(s) and LCA(a)], Benefit cost assessment (BCA), Insurance cost assessment (ICA), Social impact assessment (SIA) and alternatives assessment based on risk management measures efficiency and cost[RMM (e) and RMM (c)].Specifically, stakeholder preferences were assigned to selected methods in the categories of "no preference" ( 1). Figure 3 presents needs of regulators, SME, large industry and insurance sector with respectto sustainability assessment methods represented as force diagrams. The visualization was built using JSFiddle software. Averages across nodes (TBL and Alternative Assessment criteria) and sub-nodes (specific methods) to calculate distance from the outermost orbit. In other words, the closer the node is to the centre, the greater is the interest of the stakeholder in the method.

Stakeholders from industry are interested in a tool that supports safe and sustainable nanomanufacturing(Malsch et al. 2015b), but large industry and SME have different needs for such a tool. Large Industry users have an interest in proactively tailoring their products-in-development toward safety and sustain- ability, and have dedicated Research and Development (R\&D) units to address these needs. On the otherhand, while SMEs are interested in sustainability, theyare limited in capacity to handle complex analyses anddata generation. Due to this difference, large Industryis more interested in RA (a) and LCA (a), while SMEsare more interested in RA (s) and LCA (s). However, large industry may also use screening-level tools for prioritizing (or flagging) product development. Similarly, SMEs can use advanced tools and interpret its output with the assistance of consultants.

Regulators at the workshop included individuals who support the implementation of regulation like REACH. While existing RA frameworks are considered to cover ENM (SCENIHR 2009; OECD 2012),

regulatory agencies are making efforts to address case-specific aspects of ENM dossiers. In the case of REACH regulation, European Chemicals Agency (ECHA) requires that the nano-form of the substance needs to be registered separately from the bulk form. Itparticipates in two working groups to improve the application of RA to ENM: 
nanomaterials working group (NMWG) and group assessing already registered nanomaterials (GAARN). ECHA and regulatorsexpressed preference for SUNDS to be tailored to REACH guidelines. Quantitative ecological and human health risk assessment and the implementation of suitable risk management measures are mandatory for REACH registration and authorization dossiers. Regulators favour absolute assessment for boththreshold (i.e. substances with a linear dose-responseup to a particular limit) and non-threshold effects (i.e. substances with a linear dose-response e.g. endocrinedisrupting chemicals and carcinogens), with appropriate uncertainty analysis methods. In the event that applicants are making a socioeconomic argument for authorization, regulators also require to review LCA, BCA, SIA as well as RMM (c).

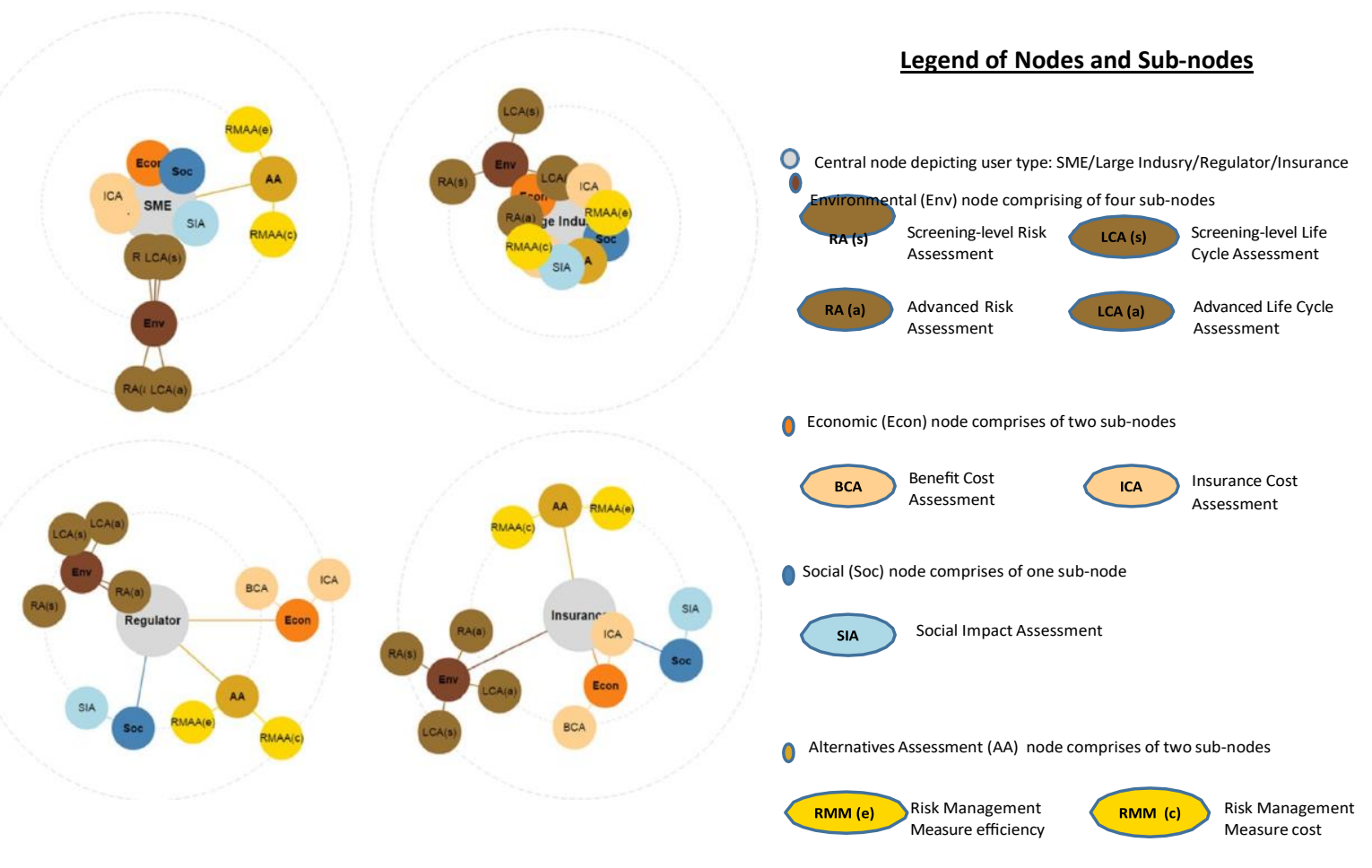

Fig. 3 User needs with respect to sustainability assessment methods

The insurance sector is extremely concerned aboutknowledge gaps in nanosafety, potential liability claims as they are called upon to accept nanotechnology production risk in a field with high scientific and economic uncertainty and no actuarial data (Mullins et al. 2013). Development of actuarial protocols and other ICA tools was deemed by the insurance sector stakeholders as a pressing need to ensure the long term sustainability of the nanotechnology. As these needs are being addressed, the insurance industry has emerged as an effective lobby for improved risk management practices in industry. Insurance providers present at the stakeholder workshop expressed a willingness to offer discretionary premium discounts if industry demonstrated an understanding of risk, regulation and Standard Operating Procedures. Insurance providers are not interested in assessment ofalternatives according to efficiency and cost, and hence the AA node has not been shown in the insurance diagram in Fig. 3.

\section{Summary and future developments}

This paper discusses current needs for nanotechnology risk management, and proposes the SUNDS conceptual decision framework as an advancement over existing risk assessment and management frameworkswith respect to seven criteria. Two of these frameworks i.e. LICARA NanoSCAN and CENARIOS standard have been included 
within the SUNDS conceptual decision framework. LICARA NanoSCAN as Tier 1 of SUNDS provides a good screening-level assessment that can be used even with limited data (Som et al. 2014). A stand-alone module based on the CENARIOS standard addresses the efficacy of organizational risk management, which is an important aspect to be addressed owing to theuncertain and fast evolving nature of nano-EHS research (Widler et al. 2016). The following para- graphs discuss how the SUNDS conceptual decision framework expands the locus from nanotechnology risk assessment and management to emerging risk governance needs.

SUNDS conceptual decision framework has a two-tier structure comprising screening and advanced toolsto address varying data availability and stakeholder needs. Currently, data may not be available to apply the SUNDS Tier 2 to all nano-enabled products. In these situations, Tier 1 results can provide some insight on nano-enabled products to the user to supportdecision-making.

SUNDS assesses TBL impacts over the life cycle of nano-enabled products (criteria 1 and 2). In addition to (eco)toxicological risks and environmental impacts, itincludes screening-level and advanced methodologiesfor economic and social impact assessment. The Benefit-Risk Assessment in the framework is not balanced in terms of being more comprehensive on therisk and costs than benefits due to case-specific natureof benefits and more developed risk research. How- ever, a comparative methodology can help choosenano-enabled product alternatives with lower risks or costs and higher benefits (criterion 5).

SUNDS includes the perspectives of regulatory, industry and insurance stakeholders from early stages of framework design through a comprehensive user elicitation process (Malsch et al. 2015a, b), to the inclusion of their criteria preferences in the decision- making. User preferences form the core of sustain- ability assessment in the SEA module (criterion 3). Further, SUNDS conceptual decision framework and tools include elements from the EU REACH regulation so that stakeholders can be guided in approachingrisk management and sustainability in a manner compatible with existing regulatory frameworks. SUNDS conceptual decision framework will adopt the two REACH authorization foci of RC (ECHA 2011a) and SEA (ECHA 2011b) within both tiers. Ourintention is not to build a DSS that is in strict compliance with REACH regulation, but to support users to approach risk management and sustainabilityin the way that is compatible with REACH regulation.SUNDS has comprehensive risk management component covering all risk management categories of the traditional hierarchy of risk control (criterion 4). Riskcontrol in SUNDS is addressed through: (a) Techno- logical Alternative and Risk Management Measures (TARMM) inventory linked to RA modules with efficiency, cost of safety-by-molecular design measures, engineering controls and personal protective equipment (Oksel et al. 2015), and (b) a stand-alone module that assesses implementation of organizational risk management based on the CENARIOS standard (Widler et al. 2016).

SUNDS conceptual decision framework is based on decision analysis, which provides two strategies to address uncertainty (criterion 6). First, it enables the utilization of latest research findings to structure the decision problem and provide useful insight on the most relevant impacts. The framework can also be linked to a methodology that supports explicit con- sideration of parameter sensitivity and uncertainty(criterion 6). SUNDS conceptual decision frameworkis also adaptive to new data and stakeholder perspectives, and is thus suitable for nanotechnology risk governance over an extended time period (criterion 7).Even during stakeholder elicitation process conductedthus far to develop the SUNDS conceptual decision framework, we have experienced and witnessed a growing understanding of nanotechnology risk management and sustainable innovation issues.

SUNDS not only supports traditional risk Management, but also has potential contribution towards Risk Governance. Risk governance in the context of nanotechnology has received limited attention until the recent past, but ongoing work is attempting to coalesce existing concepts and methodologies thatcould facilitate risk governance and in result, better define what it means in the context of nanotechnology.Broader methodologies and outcomes for stakeholderengagement in the context of nanotechnology are being reported (Isaacs et al. 2015; Malsch et al. 2015c; NNI Report 2015). In terms of the classification of risk regulation as mandatory (Breggin and Pendergrass2010) or voluntary risk regulation (Meili and Widmer2010), upcoming risk governance frameworks repre- sent a combined approach which includes mandatory elements (e.g. aspects of existing environmental regulation) but voluntary in its implementation. Cur- rent efforts include developing tools to facilitate risk governance (SRA/NSC 2016) and extend risk assessment and management to risk governance by includingstakeholder needs and perspectives (Prosafe 2015).

SUNDS conceptual decision framework forms the basis of the SUN DSS, whose beta prototype is in implementation stage. It will be tested in two case studies comprising real industrial products: antimicrobial wood 
coating formulation containing copper oxide and organic pigments used in automotive finishes. These imminent developments are expected to further improve the understanding of the links between risk management, sustainable innovation andrisk governance in specific use contexts, and facilitateholistic decision-making by stakeholders.

Acknowledgments This study was funded in part by the European Union Seventh Framework Programme [FP7/2007- 2013] under ECGA No. 604305 "SUN". This publication reflects the views only of the authors, and the European Commission and other sponsors cannot be held responsible for any use, which may be made of the information contained therein.

\section{References}

Althaus H-J, Pablo A, Bouamrane M et al (2009) Guidelines forsocial life cycle assessment of products. In: Beno^1t C, Mazijn B (eds). UNEP-DTIE, Paris

Barberio G, Scalbi S, Buttol P, Masoni P, Righi S (2014)Combining life cycle assessment and qualitative risk assessment: the case study of alumina nanofluid production. Sci Total Environ 496:122-131

Baublyte L, Mullins M, Murphy F, Tofail SA (2014) Insurancemarket perception of nanotechnology and nanomaterials risks. The Geneva Association Issue 54

Blaunstein R, Linkov I (2010) Nanotechnology risk management: an insurance industry perspective. In: Hull M, Bowman D (eds) Nanotechnology environmental health and safety. William Andrew Publishing Boston, Boston, pp 143-179

Breggin LK, Pendergrass J (2010) Regulation of nanoscalematerials under media-specific environmental laws. In:Hodge GA, Bowman DM, Maynard AD (eds) Internationalhandbook on regulating nanotechnologies. Edward Elgar Publishers, Cheltenham

Conti JA, Killpack K, Gerritzen G, Huang L, Mircheva M, Delmas M, Harthorn BH, Appelbaum RP, Holden PA(2008) Health and safety practices in the nanomaterials workplace: results from an international survey. Environ Sci Technol 42:3155-3162

De Bruyn S, Korteland M, Davidson M, Bles M (2010) ShadowPrices Handbook Valuation and weighting of emissions and environmental impacts. March 1-140

ECHA (2011) Guidance on the preparation of an application forauthorization. Available via https://www.echa.europa.eu/ documents/10162/13637/authorisation_application_en.pdf ECHA (2011) Guidance on socio-economic analysis—authorisation. Available at http://echa.europa.eu/documents/ 10162/13643/sea_authorisation_en.pdf

ECHA (2012) Guidance on information requirements andchemical safety assessment. Available via http://echa. europa.eu/guidance-documents/guidance-on-information- requirements-and-chemical-safety-assessment

Engeman CD, Baumgartner L, Carr BM, Fish AM, MeyerhoferJD, Satterfield TA, Holden PA, Harthorn BH (2012) Governance implications of nanomaterials companies' inconsistent risk perceptions and safety practices.J Nanopart Res 14:1-12

Goedkoop M, Heijungs R, Huijbregts M, De Schryver A, StruijsJ, Van Zelm R (2009) ReCiPe 2008. A life cycle impact assessment method which comprises harmonised categoryindicators at the midpoint and the endpoint level. Availableat http://www.leidenuniv.nl/cml/ssp/publications/recipe_characterisation.pdf

Gottschalk F, Kost E, Nowack B (2013) Engineered nanomaterials in water and soils: a risk quantification based on probabilistic exposure and effect modeling. Environ Tox- icol and Chem 32:1278-1287

Gottschalk F, Lassen C, Kjoelholt J, Christensen F, Nowack B (2015) Modeling flows and concentrations of nine engineered nanomaterials in the Danish environment. Int J Environ Res Public Health 12:5581-5602

Grieger KD, Linkov I, Hansen SF, Baun A (2012a) Environ- mental risk analysis for nanomaterials: review and evaluation of frameworks. Nanotoxicology 6:196-212

Grieger KD, Laurent A et al (2012b) Analysis of current research addressing complementary use of life-cycle assessment and risk assessment for engineered nanomate- rials: have lessons been learned from previous experience with chemicals? J Nanopart Res 14(7):1-23

Gunderson LH (2001) Panarchy: understanding transformations in human and natural systems. Island Press, Washington

Hansen SF, Baun A, Alstrup-Jensen K (2011) NanoRiskCat: a conceptual decision support tool for nanomaterials, DanishMinistry of the Environment

Höck J et al (2013) Guidelines on the precautionary matrix for synthetic nanomaterials. Version 3.0. Federal Office of Public Health and Federal Office for the Environment, Berne 2013, Version 3.0, Berne

Hristozov D, Gottardo S, Critto A, Marcomini A (2012) Risk assessment of engineered nanomaterials: a review of available data and approaches from a regulatory perspective. Nanotoxicology 6:880-898

Hristozov D, Gottardo S, Semenzin S, Oomen A, Bos P, Peijnenberg W, Van Tongeren M, Nowack B, Hunt N, BrunelliA, ScottFordsman J, Marcomini A (2015) Frameworks and tools for risk assessment and management of manufactured nanomaterials. Submitted to Environmental International

IRGC (2005) Risk governance: towards an integrative approach. Available via http://www.irgc.org/publications/core- concepts-of-riskgovernance/

IRGC (2007) Nanotechnology risk governance: recommendations for a global, coordinated approach to the governance of potential risks. Available at http://irgc.org/wp-content/ uploads/2012/04/PB_nanoFINAL2_2_.pdf

IRGC (2010) Risk governance deficits. Available via http://www.irgc.org/publications/core-concepts-of-risk-governance/ IRGC

(2012) An introduction to the IRGC risk governanceframework. Available via http://www.irgc.org/publications/core-concepts-ofrisk-governance/

IRGC (2015) IRGC guidelines for emerging risk governance. Available via http://www.irgc.org/publications/core-concepts-of-riskgovernance/ 
Isaacs JA, Alpert CL, Bates M, Bosso CJ, Eckelman MJ, LinkovI, Walker WC (2015) Engaging stakeholders in nano-EHSrisk governance. Environ Syst Decis 35:24-28

Linkov I, Seager TP (2011) Coupling multi-criteria decision analysis, life-cycle assessment, and risk assessment for emerging threats. Environ Sci Technol 45:5068-5074

Linkov I, Satterstrom F, Kiker G, Batchelor C, Bridges T, Ferguson E (2006) From comparative risk assessment to multi-criteria decision analysis and adaptive management:recent developments and applications. Environ Int 32:1072-1093

Linkov I, Satterstrom F, Monica JC Jr, Foss S (2009) Nano riskgovernance: current developments and future perspectives. Nanotechnol Law Bussiness 6:203

Linkov I, Anklam E, Collier ZA, Dimase D, Renn O (2014) Risk-based standards: integrating top-down and bottom- up approaches. Environ Syst Decis 34:134-137

Lux Research (2014) State of market report on nanotechnology.Available at https://portal.luxresearchinc.com/research/ report_excerpt/16215

Malsch I, Subramanian V, Semenzin E, Hristozov D, Marcomini A (2015a) Collective decision making on risk managementand sustainable manufacturing of nanomaterials and the role of decision support tools. In: Proceedings 5th STS Italia conference " a matter of design'. Milan. 12-14 June2014

Malsch I, Subramanian V, Semenzin E, Hristozov D, Marcomini A (2015b) Supporting decision-making for sustainable nanotechnology. Environ Syst Decis 35:54-75

Malsch I, Subramanian V, Semenzin E, Hristozov D, Marcomini A, Mullins M, Murphy F, Hester E, Mcalea A, Tofail SA (2015c) Empowering citizens in international governance of nanotechnologies. J Nanopart Res 17:1-19

Maynard AD (2015) The (nano) entrepreneur's dilemma. Nat Nanotechnol 10(3):199-200

Meili C, Widmer M (2010) Voluntary measures in nanotechnology risk governance: the difficulty of holding the wolf by the ears. In: Hodge GA, Bowman DM, Maynard AD (eds) International handbook on regulating nanotechnologies. Edward Elgar Publishers, Cheltenham

Mullins M, Murphy F, Baublyte L, Baublyte L, McAlea EM, Tofail SA (2013) The insurability of nanomaterial pro- duction risk. Nat Nanotechnol 8:222-224

Nanodatabase (2015) Inventory of nano-enabled products. Retrieved 07/07/2015, from http://nanodb.dk/

National Nanotechnology Initiative (2015) Stakeholder perspectives on perception, assessment, and management of the potential risks of nanotechnology. Report of the national nanotechnology initiative workshop, 10-11 Sept 2013, Washington, DC. http://www.nano.gov/node/1348. Accessed 03 Sept 2015

OECD, European Commission (2012) Series on the safety of manufactured nanomaterials No. 33: important issues on Risk Assessment of manufactured nanomaterials, Paris

Oksel C, Subramanian V, Semenzin E, Ma CY, Hristozov D, Wang X, Wilkins T, Hunt N, Costa A, Fransman W, Marcomini A (2015) Risk management along the lifecycleof nano-enabled products. Submitted to EnvironmentalScience: Nano

Powers CM, Dana G, Gillespie P, Gwinn MR, Hendren CO, Long TC, Wang A, Davis MJ (2012) Comprehensive environmental assessment: a meta-assessment approach. Environ Sci Technol 46:9202-9208

Powers CM, Grieger KD, Hendren CO, Meacham CA, Gurevich G, Lassiter MG, Money ES, Lloyd JM, Beaulieu SM(2014) A webbased tool to engage stakeholders in informing research planning for future decisions on emerging materials. Sci Total Environ 470-471:660-668

Project on Emerging Nanotechnologies (2015) Consumer products inventory. Retrieved 07/07/2015, from http:// www.nanotechproject.org/cpi

Prosafe Project (2015) Promoting the implementation of safe bydesign. Retrieved 01/02/2016, from http://www.h2020-prosafe.eu/

Renn O (2008) Risk governance: coping with uncertainty in a complex world. Earthscan Publishers, London

Renn O, Roco MC (2006) Nanotechnology and the need for riskgovernance. J Nanopart Res 8:153-191

SCENIHR (2009) Risk assessment of products of nanotechnologies. European Commission Scientific Committee on emerging and newly identified health risks, Brussels

Seear K, Peterson A, Bowman D (2009) The social and economic impacts of nanotechnologies: a literature review. Report prepared for the Department of Innovation,Industry, Science and Research. Monash University, Melbourne

Semenzin E, Lanzellotto E, Hristozov D, Critto A, Zabeo A, Giubilato E, Marcomini A (2015) Species sensitivity weighted distribution for ecological risk assessment of engineered nanomaterials: the n- $\mathrm{TiO}_{2}$ case study. EnvironToxicol Chem 34:26442659

Shatkin JA (2012) Nanotechnology: health and environmental risks. CRC Press, Boca raton

Society of Risk Analysis Nanosafety Cluster (2016) Upcoming white paper on risk governance. Retrieved 01/02/2016, from http://www.sra.org/news/sra-nanosafety-cluster

Som C, Berges M, Chaudhry Q, Dusinska M, Fernandes TF, Olsen SI, Nowack B (2010) The importance of life-cycle concepts for the development of safe nanoproducts. Toxi- colology 269:160-169

Som C, Zondervan-van den Beuken E, Van Harmelen T, Güt- tinger J, Bodmer M, Brouwer D, Buist HE, Carroll R, CollC, Fransman W, Hartmanis A, Hincapie I, Hischier R, Karachalios T, Kouravelou K, Kuijpers E, Ligthart T, Notter D, Nowack B, Seibold U, Schneider G (2014)LICARA guidelines for the sustainable competitiveness ofnanoproducts. St. Gallen, Zeist, Dübendorf

Subramanian V, Youtie J, Porter A, Shapira P (2010) Is there ashift to “active nanostructures"? J Nanopart Res 12:1-10

Subramanian V, Semenzin E, Hristozov D, Marcomini A, Lin- kov I (2014) Sustainable nanotechnology: defining, measuring and teaching. Nano Today 9:6-9

Subramanian V, Semenzin E, Zabeo A, Hristozov D,Malsch I, Saling P, Van Harmelen T, Ligthart T, Marcomini A (2016) Integrating the social impacts into risk governance of nanotechnology. In: Managing risk in nanotechnology:topics in governance, assurance and transfer, Springer series on Innovation, Technology and Knowledge Management 
Sun TY, Gottschalk F, Hungerbühler K, Nowack B (2014) Comprehensive probabilistic modelling of environmental emissions of engineered nanomaterials. Environ Pollut 185:69-76

Sweet L, Strohm B (2006) Nanotechnology—life-cycle risk management. Hum Ecol Risk Assess 12:528-551 TÜV SÜD Industrie Service (2013) Certification Standard CENARIOS ${ }^{\circledR}$. Available at http://www.tuevsued.de/ uploads/images/1219824286015340810363/CENARIOS_Zertifiziergrundlage_e.pdf

Van Duuren-Stuurman B, Vink SR, Verbist KJM, Heussen HGA, Brouwer DH et al (2012) Stoffenmanager Nano Version 1.0: a web-based tool for risk prioritization of airborne manufactured nano objects. Ann Occup Hyg 56:525-541

van Harmelen T, Korenromp R, van Deutekom C, Ligthart T, van Leeuwen S, van Gijlswijk R (2007) The price of tox- icity: methodology for the assessment of shadow prices forhuman toxicity, ecotoxicity and abiotic depletion. In: Huppes G, Ishikawa M (eds) Quantified eco-efficiency, vol

2. Springer International Publishing, Berlin, pp 105-125 van Harmelen T, Zondervan-van den Beuken EK, Brouwer DH, Kuijpers E, Fransman W, Buist HB, Ligthart TN, Hincapie' I, Hischier R, Linkov I, Nowack B, Studer J, Hilty L, SomC (2016) LICARA nanoSCAN: a tool for the self-assessment of benefits and risks of nanoproducts. Submitted to Environment International (in press)

Van Leeuwen CJ, Vermeire TG (2007) Risk assessment of chemicals: an introduction. Springer, Berlin

Widler T, Meili C, Semenzin E, Subramanian V, Zabeo A, Hristozov D, Marcomini A (2016) Organisational risk management of nanomaterials using SUNDS: the contribution of CENARIOS ${ }^{\circledR}$. In: Managing risk in nanotechnology: topics in governance, assurance and transfer. Springer series on Innovation, Technology and KnowledgeManagement (in press) 